\title{
Involvement of Fenton chemistry in rice straw degradation by the lignocellulolytic bacterium Pantoea ananatis Sd-1
}

\author{
Jiangshan Ma', Keke Zhang ${ }^{1}$, Mei Huang ${ }^{1}$, Stanton B. Hector ${ }^{2,3}$, Bin Liu' ${ }^{1}$, Chunyi Tong ${ }^{1}$, Qian Liu', Jiarui Zeng ${ }^{1}$,
}

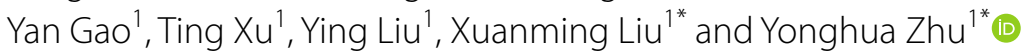

\begin{abstract}
Background: Lignocellulolytic bacteria have revealed to be a promising source for biofuel production, yet the underlying mechanisms are still worth exploring. Our previous study inferred that the highly efficient lignocellulose degradation by bacterium Pantoea ananatis $\mathrm{Sd}-1$ might involve Fenton chemistry $\left(\mathrm{Fe}^{2+}+\mathrm{H}_{2} \mathrm{O}_{2}+\mathrm{H}^{+} \rightarrow \mathrm{Fe}^{3+}+\mathrm{OH}\right.$ $\cdot+\mathrm{H}_{2} \mathrm{O}$ ), similar to that of white-rot and brown-rot fungi. The aim of this work is to investigate the existence of this Fenton-based oxidation mechanism in the rice straw degradation process of $P$. ananatis $\mathrm{Sd}-1$.
\end{abstract}

Results: After 3 days incubation of unpretreated rice straw with $P$. ananatis $\mathrm{Sd}-1$, the percentage in weight reduction of rice straw as well as its cellulose, hemicellulose, and lignin components reached 46.7, 43.1, 42.9, and $37.9 \%$, respectively. The addition of different hydroxyl radical scavengers resulted in a significant decline $(P<0.001)$ in rice straw degradation. Pyrolysis gas chromatography-mass spectrometry and Fourier transform infrared spectroscopy analysis revealed the consistency of chemical changes of rice straw components that exists between P. ananatis Sd-1 and Fenton reagent treatment. In addition to the increased total iron ion concentration throughout the rice straw decomposition process, the $\mathrm{Fe}^{3+}$-reducing capacity of $\mathrm{P}$. ananatis $\mathrm{Sd}-1$ was induced by rice straw and predominantly contributed by aromatic compounds metabolites. The transcript levels of the glucose-methanol-choline oxidoreductase gene related to hydrogen peroxide production were significantly up-regulated (at least $P<0.01$ ) in rice straw cultures. Higher activities of GMC oxidoreductase and less hydrogen peroxide concentration in rice straw cultures relative to glucose cultures may be responsible for increasing rice straw degradation, which includes Fenton-like reactions.

Conclusions: Our results confirmed the Fenton chemistry-assisted degradation model in P. ananatis Sd-1. We are among the first to show that a Fenton-based oxidation mechanism exists in a bacteria degradation system, which provides a new perspective for how natural plant biomass is decomposed by bacteria. This degradative system may offer an alternative approach to the fungi system for lignocellulosic biofuels production.

Keywords: Lignocellulose degradation, Pantoea ananatis Sd-1, Fenton chemistry, Rice straw, Bacteria degradation system

\section{Background}

Plant biomass, the most abundant terrestrial carbon source, represents a valuable feedstock for lignocellulosic biofuels [1]. To achieve complete transformation

\footnotetext{
*Correspondence: xml05@hnu.edu.cn; yonghuaz@outlook.com ${ }^{1}$ Hunan Province Key Laboratory of Plant Functional Genomics and Developmental Regulation, College of Biology, Hunan University, Changsha 410008, Hunan, People's Republic of China

Full list of author information is available at the end of the article
}

of plant biomass, a key issue is to efficiently disrupt the recalcitrant barriers of plant lignocellulose structure thus releasing fermentable sugars as well as other valuable chemicals. A number of microorganisms can carry out biomass conversion via secretion of polysaccharide- and/or lignin-degrading enzymes [2, 3]. However, these enzymes are usually too large to penetrate intact plant cell walls, leading to chemical or physical pretreatment of biomass prior to microbial conversion $[4,5]$. 
Nevertheless, a few of other microorganisms were found to be able to decompose natural lignocellulosic biomass without pretreatment. Comparing to the high energy input, harsh conditions, and toxic residues of most chemical and/or physical pretreatment strategies, these microbial conversions can be conducted under milder conditions and are more environmentally friendly. The white-rot fungi (notably Phanerochaete chrysosporium) and the brown-rot fungi (such as Serpula lacrymans) are classified under these kinds of microorganisms. Both these organisms have been extensively studied for their lignocellulose biodegradation mechanisms [2, 6-9]. It is inferred that white-rot and brown-rot fungi contain a Fenton-based oxidation model to modify the lignocellulose backbone to make it amenable to enzymatic hydrolysis [10, 11]. Hydroxyl radical $(\mathrm{OH} \cdot)$, generated extracellularly via the Fenton chemistry $\left(\mathrm{Fe}^{2+}+\mathrm{H}_{2} \mathrm{O}_{2}+\right.$ $\mathrm{H}^{+} \rightarrow \mathrm{Fe}^{3+}+\mathrm{OH} \cdot+\mathrm{H}_{2} \mathrm{O}$ ), is such an oxidation agent $[9,12]$. These hydroxyl radicals randomly attack lignocellulose at close proximity and disrupt its structural matrix through internal cleavage of cellulose chains and modification of lignin [13]. Besides, some reports have shown the existence of this Fenton-based oxidation mechanism in other fungi. For example, Xie et al. [14] showed that the Fenton system-mediated hydroxyl radicals play an important role in the lignin degradation process of oleaginous fungus Cunninghamella echinulata FR3. In recent years, the emerging role of bacteria in lignocellulose degradation has been the focus of much research attention, yet its mechanism is less well-studied compared to that of lignocellulolytic fungi. Previous studies have shown molecular weight similarities between bacterial and fungal lignocellulolytic enzymes [15], hence it is expected that bacteria may possess analogous Fenton-like oxidation mechanisms. However, to date, no reports have documented Fenton-based oxidation in bacteria lignocellulose conversion system.

In our previous study, we isolated an endophytic bacterium Pantoea ananatis Sd-1 (China General Microbiological Culture Collection Centre, no. 6698) and found that it has the capacity to simultaneously degrade cellulose, hemicellulose, and lignin [16]. To our knowledge, these characteristics have only been reported for very few microorganisms especially white-rot fungi. We demonstrated that $P$. ananatis $\mathrm{Sd}-1$ was capable of secreting a plethora of lignocellulolytic enzymes while growing on rice straw-containing media. In addition, bioinformatic analysis inferred that a Fenton-like reaction mechanism might exist as a part of the $P$. ananatis Sd-1 lignocellulose degradation system [17]. In this study, in order to confirm Fenton chemistry-assisted degradation in $P$. ananatis $\mathrm{Sd}-1$, we evaluated the activity of $P$. ananatis $\mathrm{Sd}-1$ on natural rice straw as well as in the presence of different hydroxyl radical scavengers, including dimethylsulfoxide (DMSO), mannitol, thiourea, and ethanol. We analyzed chemical structure variations of rice straw after treatment with $P$. ananatis $\mathrm{Sd}-1$ by pyrolysis gas chromatography-mass spectrometry (Py-GC/MS) and Fourier transform infrared (FTIR) spectroscopy. In addition, we assessed the total iron ion concentration in the system and $\mathrm{Fe}^{3+}$-reducing capacity of $P$. ananatis $\mathrm{Sd}-1$, and verified the presence of low molecular weight products such as $\mathrm{Fe}^{3+}$-reductant by gas chromatography-mass spectrometry (GC-MS) analysis. Furthermore, gene and enzymes expression levels responsible for hydrogen peroxide generation and hydrogen peroxide concentration were also evaluated.

\section{Results and discussion}

Natural rice straw degradation characteristics of $P$. ananatis Sd-1

Our previous report on the lignocellulose degradation capacity of $P$. ananatis $\mathrm{Sd}-1$ was based on alkaline-pretreated rice straw [16]. In order to determine whether $P$. ananatis $\mathrm{Sd}-1$ was able to degrade the natural lignocellulosic substrates, the bacterium was cultured on unpretreated [except underwent necessary autoclaving, because sterilization did not liberate more reducing sugar from rice straw to liquid than that of the unsterilized medium (data not shown)] rice straw medium and the resulting reducing sugars were measured. As shown in Fig. 1a, $P$. ananatis Sd-1 grew optimally in rice straw medium during the first 3 days of incubation and correspondingly, large yields of the reducing sugars were observed compared with that of non-inoculated control. In addition, the mass of the total rice straw (Fig. 1b), cellulose (Fig. 1c), hemicellulose (Fig. 1d), and lignin (Fig. 1e) contents all decreased substantially in the initial 3 days of treatment with the percentage weight loss reaching $46.7,43.1,42.9$, and $37.9 \%$, respectively, while they changed almost nothing in control (data not shown). Interestingly, this is directly proportionate to the bacterial growth and the reducing sugar production. After the initial period, reducing sugar content increased slightly while there was a decline in bacterial growth. Equally, the weight reductions of total rice straw, cellulose, hemicellulose, and lignin were only $2.2,2.2,3.4$, and $3.6 \%$ respectively between 3 and 6 days. These results indicate that $P$. ananatis $\mathrm{Sd}-1$ is able to partially depolymerize natural rice straw into its reducing sugars components. To date, very few bacteria have been reported to possess the capacity to decompose natural lignocellulosic substrates [2]. Kumar et al. [18] demonstrated that the maximum weight reduction of $49 \%$ was observed for Pseudoxanthomonas sp. R-28 on day 3 when incubated with unpretreated rice straw. Wang et al. [19] reported that 

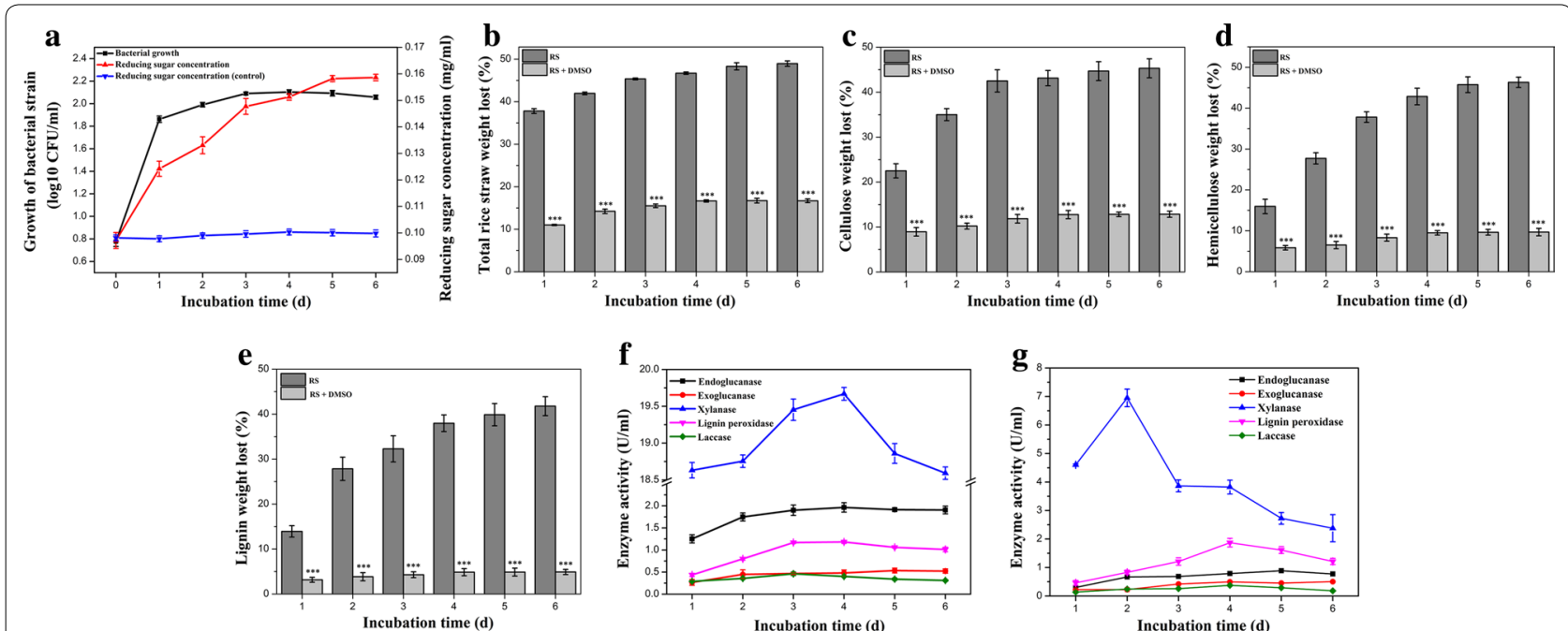

Fig. 1 Growth of bacterial strain and reducing sugars production (a); percentage of weight loss for total rice straw (b), cellulose (c), hemicellulose (d), and lignin (e) in the presence (RS + DMSO) and absence (RS) of DMSO. Enzymes activities of endoglucanase, exoglucanase, xylanase, lignin peroxidase, and laccase in the absence $(\mathbf{f})$ and presence of DMSO (g) during the degradation of rice straw by P. ananatis Sd-1. Control: non-inoculated cultures. The values represent the means of three replicates with the standard deviation (SD). The asterisks attached to data points represent statistically significant differences when DMSO was added versus not added. (statistical significance: ${ }^{* *} P<0.001$ )

the unpretreated rice straw was degraded most expeditiously by bacterial consortium XDC-2 before day 6 with the weight loss of rice straw and its cellulose, hemicellulose, and lignin components reaching 39.6, 9.7, 84.4, and $30.2 \%$, respectively. Our evidences suggest that $P$. ananatis $\mathrm{Sd}-1$ possesses comparable natural rice straw bioconversion abilities to these reported bacteria.

Our previous research showed $P$. ananatis Sd-1 to possess an arsenal of enzymes required for cellulose, hemicellulose, and lignin degradation [17]. Activities of several of these lignocellulolytic enzymes (endoglucanase, exoglucanase, xylanase, lignin peroxidase, and laccase) were measured during the rice straw degradation process. As shown in Fig. 1f, in correlation with the rapid degradation of rice straw, increased activities were observed for all detected enzymes during the logarithmic phase, i.e., the first 3 days of incubation. However, maximum activity of most of enzymes was reached on day 4 for endoglucanase, xylanase, and lignin peroxidase enzymes with the exception of the exoglucanase which reached optimal activity on day 5 . Analysis of these results suggested that in addition to enzymatic hydrolysis, another oxidation pathway at the incipient stage of rice straw degradation in $P$. ananatis $\mathrm{Sd}-1$ may exist. It is assumed that during this process, the rice straw structure weakens and exposes its cellulose, hemicellulose, and lignin components to relevant lignocellulolytic enzymes, giving rise to induction and increased expression of these enzymes.

With regards to laccase enzymes, it was speculated that it may oxidize some low molecular weight mediators to diffusible free radicals which could act as direct oxidants of lignocellulose in vitro; however, these mediators were not detected [20]. In our study, the maximum laccase activity was reached on day 3 , which is in correlation with this proposed oxidization role for laccases. However, the detected laccase activity was maintained at much lower levels (maximum value $0.46 \mathrm{U} / \mathrm{ml}$ ) compared to that of other reported bacteria (normally about $1 \mathrm{U} / \mathrm{ml}$ ) [2123]. This indicated that laccase might play a partial role in the oxidation of lignocellulose. These results support our hypothesis that another oxidation mechanism might assist $P$. ananatis $\mathrm{Sd}-1$ degradation of rice straw.

\section{Influence of hydroxyl radical scavenger on rice straw degradation efficiency of $P$. ananatis Sd-1}

Fenton-based oxidation via hydroxyl radicals generated by Fenton chemistry has been found in fungi for plant cell wall decomposition [12]. Jung et al. [24] also applied Fenton chemistry using $\mathrm{FeCl}_{3}$ and hydroxyl peroxide to pretreat rice straw. In order to verify whether a Fentonlike reaction exists as part of the process of rice straw degradation by $P$. ananatis $\mathrm{Sd}-1$, we tested if the degradative efficiency is hydroxyl radical dependent. DMSO has been widely used as a hydroxyl radical scavenger [25]. The weight loss of rice straw (Fig. 1b) and its components (Fig. 1c-e) was significantly $(P<0.001)$ decreased in the presence of DMSO relative to that in the absence of DMSO, indicating the involvement of hydroxyl radicals in lignocellulose degradation. Bacterial growth remained unaffected, while reducing sugar production decreased 
due to the presence of DMSO (Additional file 1: Figure S1). Compared to the result in the absence of DMSO (Fig. 1a), we ruled out the possibility that the observed inhibition of DMSO on lignocellulose degradation was due to its toxicity on bacterium. Similar effects of DMSO were demonstrated by Grinhut et al. [13] during humic acid bleaching by Trametes sp. M23 which involved Fenton-like reaction mechanisms. Forney et al. [26] also reported that lignin degradation by $P$. chrysosporium which generated hydroxyl radicals via Fenton chemistry was markedly suppressed in the presence of the hydroxyl radical scavengers, benzoate, and mannitol. We also detected the effects of several other hydroxyl radical scavengers including mannitol, thiourea, and ethanol on rice straw degradative efficiency of $P$. ananatis Sd-1. Similar to that of DMSO, the degradation efficiencies of rice straw as well as its components were all significantly suppressed by these three hydroxyl radical scavengers after 6 days of incubation (Additional file 2: Figure S2a). These results added certainty that our conclusions were not an artifact of some other aspect of DMSO-related chemistry.

Fenton reaction can also affect the sugar production and degradation during the lignocellulose degradation [27]. Sugars (glucose, xylose, and arabinose), furfural (derived from pentoses), and 5-hydroxymethylfurfural (HMF, derived from hexoses) during the $P$. ananatis Sd-1 and Fenton reagent treatment are shown in Additional file 3: Table S1. Sugars and furfural concentrations all decreased in the presence of DMSO relative to that in the absence of DMSO during the incubation time. The result from Fenton reagent treatment is similar to that of the first two days of P. ananatis Sd-1 treatment. It is worth noting that, when DMSO was added, the appearance of methanesulfinic acid (product from the reaction of DMSO and hydroxyl radical) in the first 3 days of incubation was observed and the maximum of it was detected on day 2 (Additional file 4: Figure S3). These results provide evidences for the suggestion mentioned above that Fenton reactions play a pivotal role at the incipient stage of the plant cell wall decomposition as part of the degradation repertoire of $P$. ananatis $\mathrm{Sd}-1$.

The effect of DMSO on lignin degradation (Fig. 1e) (an average of $85.6 \%$ decrease) is higher than that of cellulose (Fig. 1c) and hemicellulose (Fig. 1d) (an average of 69.4 and $75.6 \%$ decrease, respectively), highlighting the involvement of hydroxyl radicals in lignin modification. This was in contrast to reports that Fenton chemistry contributed more in cellulose degradation than in modifying and degrading lignin in several white-rot fungi with cellobiose dehydrogenase-mediated Fenton chemistry $[28,29]$. The role of cellobiose dehydrogenase includes activating hydrolytic cellulases and iron reduction for Fenton chemistry in those white-rot fungi [30], while we found no genes encoding cellobiose dehydrogenase in the genome of $P$. ananatis Sd-1 [17]. Thus we speculated that the reason of the different effects of Fenton chemistry contribution on cellulose and lignin degradation between $P$. ananatis $\mathrm{Sd}-1$ and those white-rot fungi might be the diverse iron reduction system between them.

It should be noted that DMSO was reported to affect the activities of lignocellulolytic enzymes [31]. As shown in Fig. 1g, the activities of endoglucanase, exoglucanase, xylanase, and laccase decreased average of 61.5, $14.6,78.6$, and $31.1 \%$, respectively, while lignin peroxidase activity increased average of $27.2 \%$, in presence of DMSO during the degradation process of rice straw by $P$. ananatis Sd-1. Besides, those enzymes activities were all suppressed at various extents in the presence of other three hydroxyl radical scavengers (mannitol, thiourea, and ethanol) (Additional file 2: Figure S2b-d). This suggested that in addition to the reduction of hydroxyl radical, the hydroxyl radical scavengers might also affect the lignocellulolytic enzymes activities and thus inhibit the rice straw degradation by $P$. ananatis $\mathrm{Sd}-1$.

\section{Chemical structure variation of lignocellulose in rice straw after $P$. ananatis $S d-1$ treatment}

Reaction to hydroxyl radicals can result in several alterations to lignin units, including side chain oxidation, hydroxylation, demethylation, and demethoxylation [9]. In order to obtain detailed insight into the chemical changes in the lignin structure of rice straw treated with $P$. ananatis Sd-1, Py-GC/MS analysis was performed. Pyrolysis products from rice straw lignin are classified as hydroxyphenyl, guaiacol, and syringol units according to their phenyl group structure. As shown in Fig. 2, Syringol was undetected in residual rice straw after $P$. ananatis $\mathrm{Sd}-1$ or Fenton reagent treatment. The content of hydroxyphenyl relative to guaiacol increased after $P$. ananatis $\mathrm{Sd}-1$ treatment (4.47 vs 0.41 of control). Fenton reagent caused guaiacol to disappear while the hydroxyphenyl occupied a much higher concentration compared to the control. These results indicated that both lignin modification by $P$. ananatis $\mathrm{Sd}-1$ as well as Fenton reagent were mainly through demethylation and demethoxylation reactions. Similarly, Filley et al. [32] reported Fenton chemistry demethylation of lignin in spruce sapwood when degraded by brown-rot fungi, Postia placenta and Gloeophyllum trabeum. Rineau et al. [33] found that syringyl units in the organic matter from forest litter were both demethoxylated and demethylated by Paxillus involutus through Fenton chemistry. However, as aforementioned that laccase in $P$. ananatis Sd-1 might also play a partial role in the oxidation of lignocellulose including lignin demethylation, further studies are needed to distinguish whether the demethylation of lignin is caused by Fenton chemistry or laccase. 


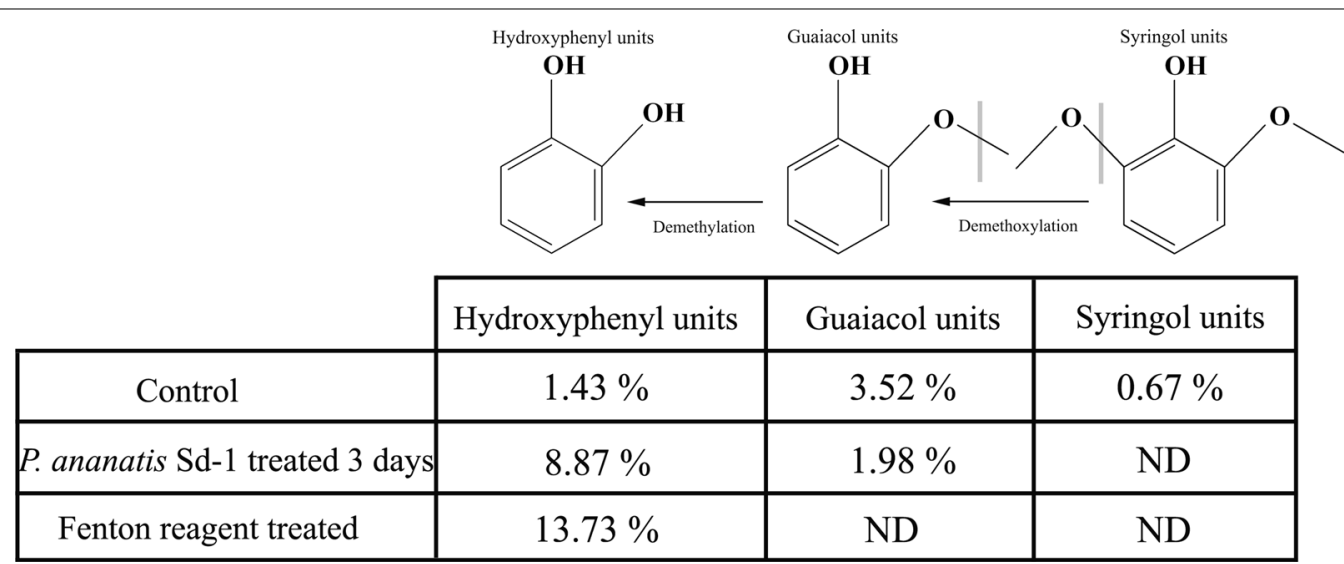

Fig. 2 Py-GC/MS analysis of rice straw. Relative peak areas of lignin-subunit pyrolysates detected by Py-GC/MS from rice straw without treatment (control), after Fenton reagent treatment and 3 days of $P$. ananatis Sd-1 treatment. ND means not detected

In addition, the Fourier transform infrared (FTIR) spectra of both Fenton reagent and P. ananatis Sd-1 treated rice straw gave similar characteristic transmission bands (Additional file 5: Figure S4). Compared to the control, the appearance of an additional peak $\left(\sim 1730 \mathrm{~cm}^{-1}\right)$ (as black arrow indicated) located in the carbonyl groups region was also indicative of oxidative degradation through Fenton-like reaction. Since the formation of carbonyl groups can be attributed to ring opening reactions of polysaccharides and aromatic moieties within lignin by oxidation reaction [34], this is similar to the previous report of Rineau et al. [33], which detected sharp carbonyl groups signal in the FTIR spectrum of Paxillus involutus treated cellulose which was shown to be associated with the Fenton reaction mechanism. Consequently, cumulative findings allude to the existence of Fenton chemistry system in $P$. ananatis $\mathrm{Sd}-1$.

\section{Induced $\mathrm{Fe}^{3+}$-reducing activity in $P$. ananatis $\mathrm{Sd}-1$ degradation system}

Fenton chemistry involves a redox cycling process, and a crucial factor is a system for reduction of $\mathrm{Fe}^{3+}$ to $\mathrm{Fe}^{2+}$ [35]. $\mathrm{Fe}^{2+}$ then reacts with hydrogen peroxide to form hydroxyl radical [36]. Thus, the hydroxyl radical level is influenced by $\mathrm{Fe}^{3+}$-reducing capacity [14]. In this study, we measured the $\mathrm{Fe}^{3+}$-reducing activity of $P$. ananatis Sd-1 when it was cultured on different carbon sources. As shown in Fig. 3, although the $\mathrm{Fe}^{3+}$-reducing activities on rice straw and glucose substrates kept the same pattern of variation, the capacities were significantly increased (at least $P<0.01$ ) in the presence of rice straw relative to glucose, especially on day 3 . The significant induction of $\mathrm{Fe}^{3+}$-reducing activity throughout the biomass decomposition process supports our hypothesis that the Fenton chemistry system might play an

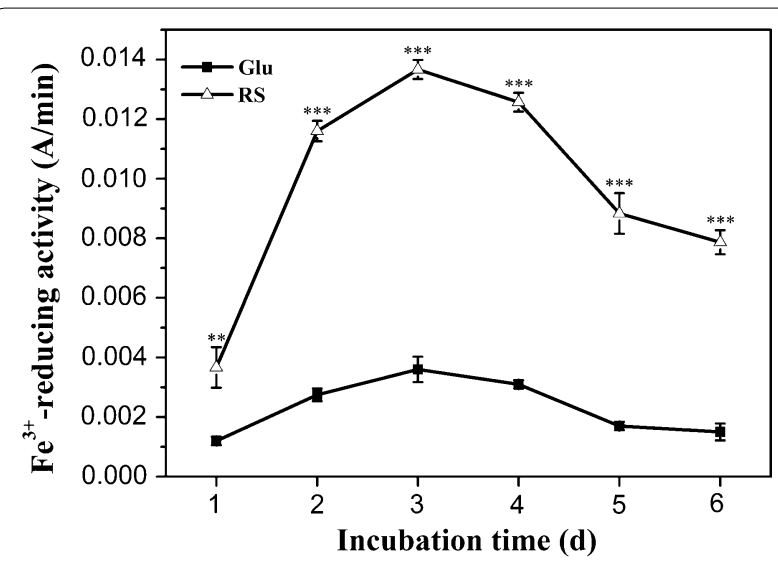

Fig. 3 Time course of $\mathrm{Fe}^{3+}$-reducing activity of $P$. ananatis $\mathrm{Sd}-1$ grown on glucose and rice straw substrates. Glu glucose substrate, $R S$ rice straw substrate. The values represent the means of the three replicates with the standard deviation (SD). The asterisks attached to data points represent statistically significant differences from the glucose medium (statistical significance: ${ }^{* *} P<0.01,{ }^{* * *} P<0.001$ )

important role in process of lignocellulose degradation by $P$. ananatis $\mathrm{Sd}-1$. Besides, to confirm that if soluble iron ion was liberated from rice straw to cultures and was favorable for Fenton reaction, the total iron ion concentration in rice straw cultures was determined. As shown in Fig. 4, the total iron ion concentration kept increasing across the entire incubation when inoculated with $P$. ananatis $\mathrm{Sd}-1$, while it was almost unchanging in control. The significant induction of $\mathrm{Fe}^{3+}$-reducing activity and increased total iron ion concentration throughout the biomass decomposition process supported our hypothesis that the Fenton chemistry system might play an important role in the process of rice straw degradation by $P$. ananatis Sd-1. 


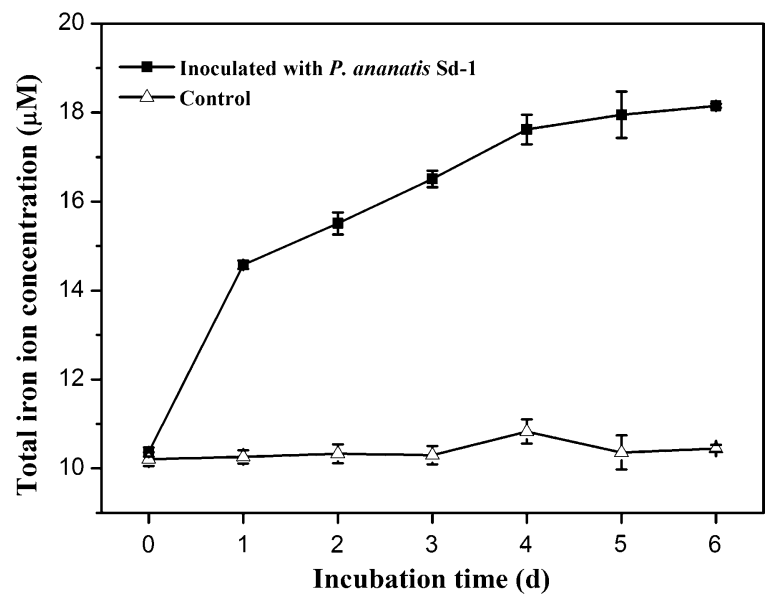

Fig. 4 The variation of total iron ion concentration in cultures during the degradation process of rice straw with $\mathrm{P}$. ananatis $\mathrm{Sd}-1$ and without inoculation (control)

In basidiomycete fungi, $\mathrm{Fe}^{3+}$ reduction is performed through three different mechanisms: (i) iron-reducing enzymes including ferric reductases and cellobiose dehydrogenase [37]; (ii) low molecular weight glycopeptides [38]; and (iii) redox cycling by low molecular weight metabolites, such as benzoquinones and involutin $[35,39,40]$. However, no genes encoding iron-reducing enzymes and low molecular weight glycopeptides were found in the genome of $P$. ananatis Sd-1 [17]. Therefore, we assume that $\mathrm{Fe}^{3+}$-reducing activity might be accomplished by extracellular low molecular weight products. Thus, both the secreted proteins and low molecular weight products from degraded rice straw were extracted from $P$. ananatis $\mathrm{Sd}-1$ cultures on day 3 and were evaluated for $\mathrm{Fe}^{3+}$-reducing activity. As shown in Fig. 5a, the $\mathrm{Fe}^{3+}$-reducing activity value of low molecular weight products $(0.0138 \mathrm{~A} / \mathrm{min})$ was significantly $(P<0.001)$ higher than that of the secreted proteins $(0.0037 \mathrm{~A} / \mathrm{min})$.

Using qualitative GC-MS, we further identified the type of low molecular weight products from $P$. ananatis Sd-1-degraded rice straw. The total ion chromatograms (TIC) corresponding to extracted compounds from control and treated samples are shown in Additional file 6: Figure S5 and their peaks identity are listed in Table 1. A number of small molecular aromatic metabolites, such as phenol (RT 14.70), benzoic acid (RT 17.42), benzeneacetic acid (RT 17.79), acetophenone (RT 19.44), 4-hydroxy-3-methoxybenzoic acid (RT 20.42), phthalic acid (RT 20.91), 4-hydroxyphenylacetic acid (RT 21.58), and benzene (RT 22.25) which are considered as the basic units of the lignin polymer were only detected in the samples treated by $P$. ananatis $\mathrm{Sd}-1$ for 3 days. In addition, some fatty acid compounds such as propanoic acid (RT 10.29), pentanoic acid (RT 12.54), octanoic acid (RT 17.37), decanoic acid (RT 18.13), nonanoic acid (RT 18.30), tetradecanoic acid (RT 21.45), and pentadecanoic acid (RT 21.94) which were generated through aromatic ring opening were also only presented in treated samples. The appearance of these metabolites confirmed again that the lignin structure of rice straw was decomposed by $P$. ananatis Sd-1. More importantly, we speculated that the $\mathrm{Fe}^{3+}$-reducing activity could be attributed to the presence of phenol, 4-hydroxy-3-methoxybenzoic acid, and 4-hydroxyphenylacetic acid which contained hydroxyl
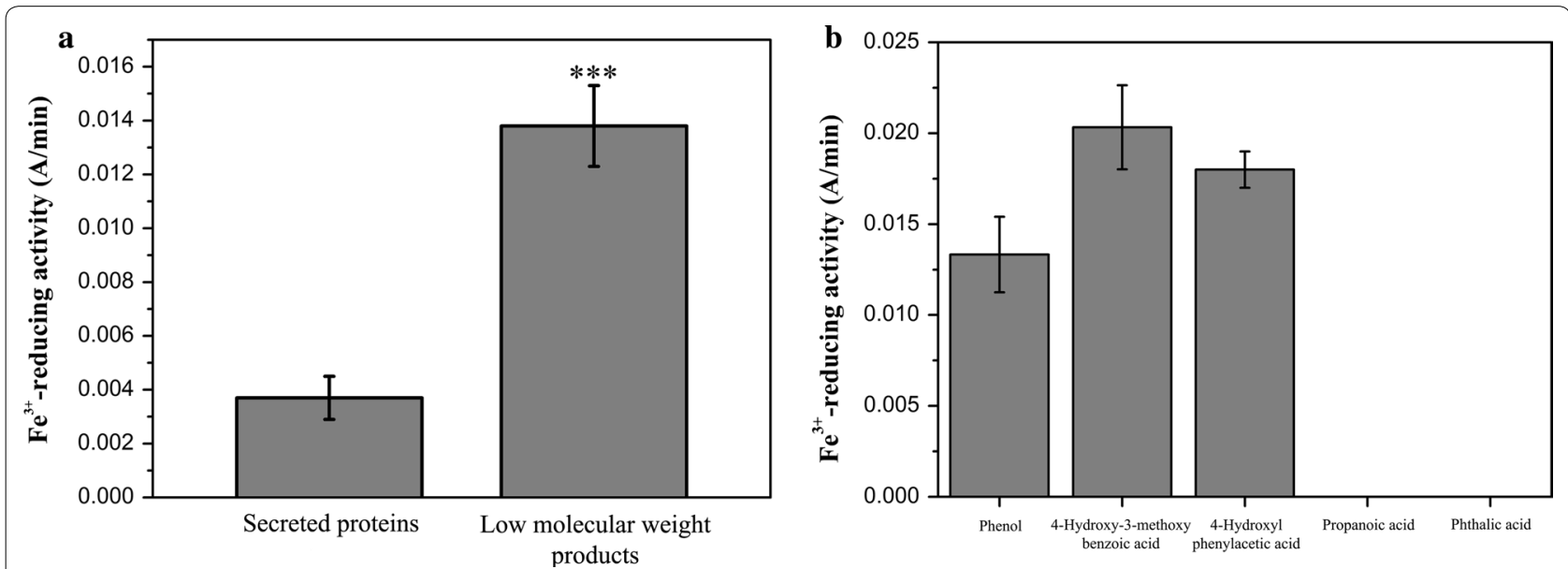

Fig. $5 \mathrm{Fe}^{3+}$-reducing activity of the secreted proteins and low molecular weight products extracted from P. ananatis Sd-1 cultures containing rice straw on day 3 (a). Fe ${ }^{3+}$-reducing activity of pure standards of phenol, 4-hydroxy-3-methoxybenzoic acid, 4-hydroxyphenylacetic acid, propanoic acid, and phthalic acid solutions (75 $\mu \mathrm{M}$ concentration) (b). The values represent the means of the three replicates with the standard deviation (SD). Asterisks represent significant differences from secreted proteins (statistical significance: ${ }^{* * *} P<0.001$ ) 
Table 1 Identification of metabolites as trimethylchlorosilane (TMS) derivatives from rice straw samples

\begin{tabular}{llll}
\hline Retention time & Compound & Control $^{\mathbf{a}}$ & Treated $^{\mathbf{b}}$ \\
\hline 10.29 & Propanoic acid & - & + \\
12.54 & Pentanoic acid & - & + \\
14.70 & Phenol & - & + \\
17.37 & Octanoic acid & - & + \\
17.42 & Benzoic acid & - & + \\
17.79 & Benzeneacetic acid & - & + \\
18.13 & Decanoic acid & - & + \\
18.30 & Nonanoic acid & - & + \\
19.44 & Acetophenone & - & + \\
20.42 & 4-Hydroxy-3-methoxybenzoic & - & + \\
& acid & & + \\
20.91 & Phthalic acid & - & + \\
21.45 & Tetradecanoic acid & - & + \\
21.58 & 4-Hydroxyphenylacetic acid & - & + \\
21.94 & Pentadecanoic acid & - & + \\
22.25 & Benzene & - & + \\
22.41 & Hexadecanoic acid & + & + \\
23.51 & Octadecanoic acid & + & + \\
\hline
\end{tabular}

${ }^{a}$ Non-inoculated (control) rice straw samples

b P. ananatis Sd-1 degraded rice straw samples

phenolic groups, due to the fact that hydroxybenzene derivatives have been found as the most efficient $\mathrm{Fe}^{3+}$ reductants [12, 41]. Aguiar et al. [42] showed that the identified 4-hydroxy-3-methoxybenzoic acid extracted from a wood chip culture treated with Ceriporiopsis subvermispora possesses $\mathrm{Fe}^{3+}$-reducing ability.

Therefore, pure standards of phenol, 4-hydroxy-3-methoxybenzoic acid, and 4-hydroxyphenylacetic acid as well as another propanoic acid and phthalic acid (without hydroxyl phenolic groups) were assayed for $\mathrm{Fe}^{3+}$-reduction. As shown in Fig. 5b, phenol, 4-hydroxy-3-methoxybenzoic acid, and 4-hydroxyphenylacetic acid all exhibited distinct $\mathrm{Fe}^{3+}$-reduction capacities, while propanoic acid and phthalic acid could not be detected. The compound 4-hydroxy-3-methoxybenzoic acid showed the highest $\mathrm{Fe}^{3+}$-reducing ability among the three compounds, whereas lowest activity was detected for phenol. These results coincided with reports that compounds containing only one hydroxyl phenolic groups reacted weakly with iron compared to those containing two or three hydroxyl phenolic groups [12]. Our evidence suggests that hydroxyl phenolic groups containing aromatics in low molecular weight products are predominantly responsible for $\mathrm{Fe}^{3+}$ reducing activity. This provides evidence for the existence of Fenton-based reaction system in $P$. ananatis Sd-1 degradation process.

\section{Hydrogen peroxide production and consumption in $P$. ananatis Sd-1 degradation process}

In brown-rot fungi Fenton chemistry system, high levels of $\mathrm{Fe}^{3+}$-reducing activity and hydrogen peroxide generation lead to plant cell wall biodegradation. Hydrogen peroxide is metabolically generated by glucose-methanolcholine (GMC) oxidoreductases such as glucose oxidase, pyranose oxidase, and radical oxidases in basidiomycetes fungi [43]. In our previous bioinformatic analysis for $P$. ananatis Sd-1 genome, we identified a GMC oxidoreductase (GenBank: Y903_RS0107765) as the pyranose oxidase, which catalyzes the oxidation of D-glucose and several other aldopyranoses to yield 2-keto sugars and hydrogen peroxide [17, 44]. We monitored and compared the expression of this GMC oxidoreductase gene in cultures incubated with rice straw or glucose through quantitative real-time PCR (RT-qPCR). As shown in Fig. 6a, an increase in gene transcript levels was recorded for rice straw cultures until day 4. Across the entire incubation period with the exception of day 2, the gene transcript levels in rice straw cultures were significantly higher (at least $P<0.01)$ compared to glucose cultures. This suggested that the expression of $P$. ananatis $\mathrm{Sd}-1$ GMC oxidoreductase gene was efficiently induced by lignocellulosic substrates. Activities of GMC oxidoreductase during growth of $P$. ananatis $\mathrm{Sd}-1$ on glucose and rice straw substrates were then detected. As shown in Fig. 6b, the GMC oxidoreductase activities kept increasing until day 4 on both substrates, while it was significantly higher (at least $P<0.05)$ in rice straw cultures relative to glucose cultures during the whole incubation time. The variation tendency of GMC oxidoreductase activity was consistent with the gene expression levels results. We also assayed the concentration of hydrogen peroxide in rice straw and glucose cultures. As shown in Fig. 6c, the hydrogen peroxide concentration in rice straw cultures was significantly lower than that in glucose cultures $(P<0.001)$ throughout the entire incubation period. This is in contrast to the higher GMC oxidoreductase transcript levels and its enzyme activities in rice straw cultures. A similar observation was reported by Grinhut et al. [13] that hydrogen peroxide concentration in Trametes sp. M23 cultures was lower in the presence of humic acid degradation. Our observation indicates a linear relationship between increasing rice straw decomposition (Fig. 1b), $\mathrm{Fe}^{3+}$-reducing activities (Fig. 3), and the reduction of hydrogen peroxide during the incubation with $P$. ananatis Sd-1. It is suspected that lower hydrogen peroxide levels in rice straw cultures can be attributed to its growing consumption for reacting with $\mathrm{Fe}^{2+}$ to decompose lignocellulose. In addition, hydrogen peroxide is also an essential co-substrate for lignin peroxidase during lignin 

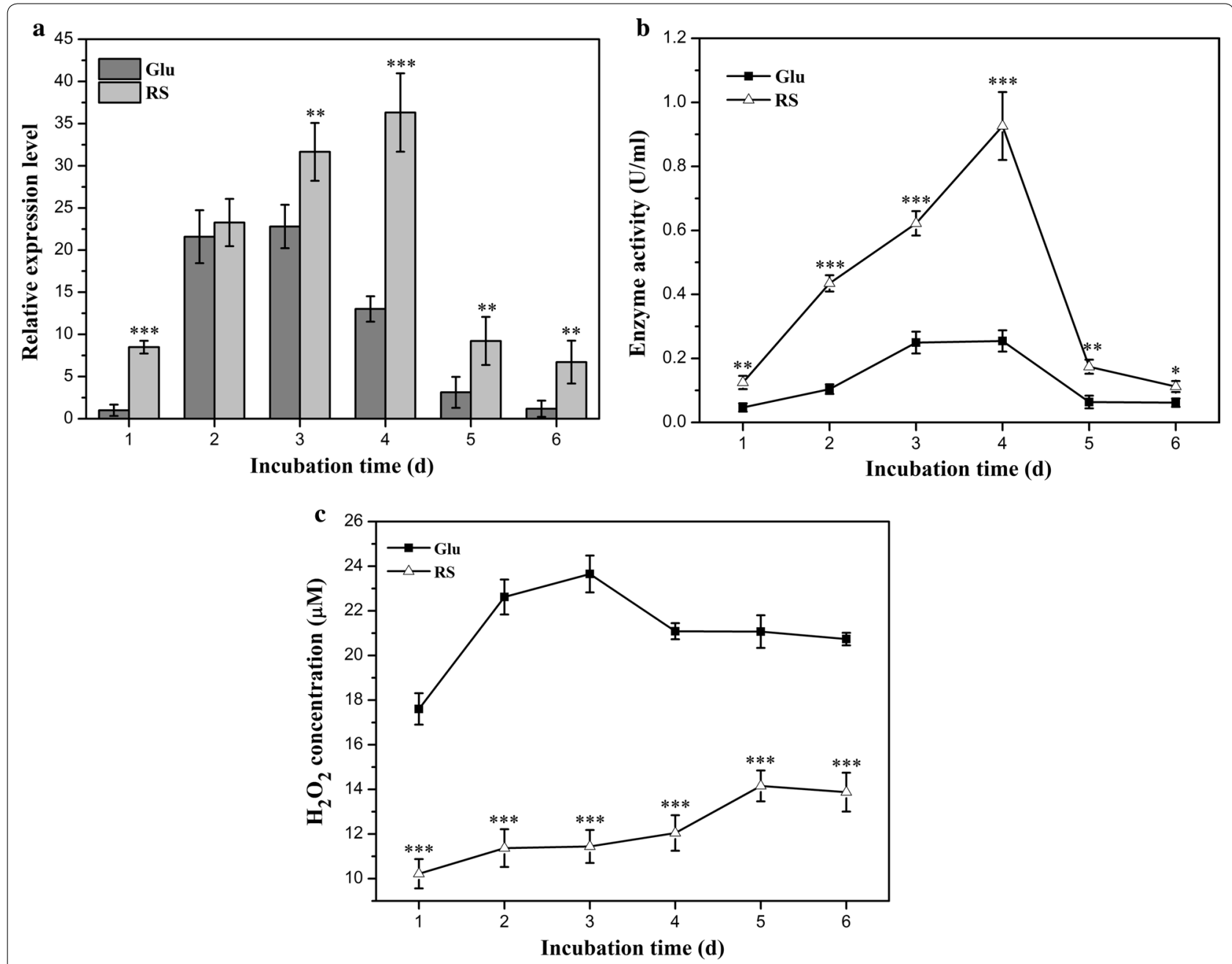

Fig. 6 Hydrogen peroxide production and consumption analysis. GMC oxidoreductase gene (Y903_RS0107765) relative expression levels of $P$. ananatis Sd-1 grown in the presence of glucose (Glu) and rice straw (RS) substrates (a). Enzyme activity of GMC oxidoreductase during growth of P. ananatis Sd-1 on glucose (Glu) and rice straw (RS) substrates (b). Hydrogen peroxide concentration during growth of $P$. ananatis $\mathrm{Sd}-1$ on glucose $(\mathrm{Glu})$ and rice straw (RS) substrates $(\mathbf{c})$. The values represent the means of the three replicates with the standard deviation (SD). Asterisks represent significant differences from the glucose cultures (statistical significance: ${ }^{*} P<0.05,{ }^{* *} P<0.01,{ }^{* * *} P<0.001$ )

degradation, and so the loss of hydrogen peroxide might also be due to its role in enzymatic hydrolysis of lignin.

\section{Conclusion}

The endophytic bacterium $P$. ananatis Sd-1 was shown to effectively degrade the natural lignocellulosic biomass, rice straw. The rate of rice straw degradation did not coincide with the lignocellulolytic enzymes activities and was significantly decreased in the presence of different hydroxyl radical scavengers. These alluded to the existence of a Fenton-based oxidation model, which was illustrated through the action of Fenton system-mediated hydroxyl radicals. The structural variation of rice straw constituents after treatment by $P$. ananatis $\mathrm{Sd}-1$ was similar to that of Fenton reagent-treated samples. The crucial factors for Fenton chemistry, the $\mathrm{Fe}^{3+}$-reducing capacity, and hydrogen peroxide production (indicated by transcript levels of GMC oxidoreductase gene and its enzyme activities) in $P$. ananatis $\mathrm{Sd}-1$ were significantly up-regulated in rice straw cultures. The low molecular weight products with hydroxyl phenolic groups might be responsible for $\mathrm{Fe}^{3+}$-reducing activity. The decrease of hydrogen peroxide in rice straw cultures relative to glucose cultures was consistent with the increasing rice straw degradation and $\mathrm{Fe}^{3+}$-reducing activities. These characteristics for Fenton reaction using $\mathrm{Fe}^{2+}$ and hydrogen peroxide confirmed the participation of Fenton chemistry system in the degradation process of rice straw 
by $P$. ananatis $\mathrm{Sd}-1$. To our knowledge, this is the first discovery of a Fenton-based oxidation mechanism from a bacteria lignocellulose degradation system, which is valuable for the lignocellulosic bioenergy industry.

\section{Methods}

\section{Growth of microorganism}

Pantoea ananatis $\mathrm{Sd}-1$ was obtained as previously reported [16]. Rice straw (obtained from Changsha, China) was washed thoroughly with distilled water, dried, and ground to pass through 40-mesh screen. $P$. ananatis Sd-1 was grown in the Luria-Bertani broth (LB) medium and incubated at $30{ }^{\circ} \mathrm{C}$ with shaking at $170 \mathrm{rpm}$ to the logarithmic growth phase. Then $1 \mathrm{ml}$ of culture was aseptically inoculated into $100 \mathrm{ml}$ mineral salt medium containing rice straw (10.0 g rice straw, $2.0 \mathrm{~g}\left(\mathrm{NH}_{4}\right)_{2} \mathrm{SO}_{4}$, $1.0 \mathrm{~g} \mathrm{KH}_{2} \mathrm{PO}_{4}, 1.0 \mathrm{~g} \mathrm{KH}_{2} \mathrm{PO}_{4}, 0.2 \mathrm{~g} \mathrm{MgSO}_{4}, 0.1 \mathrm{~g} \mathrm{CaCl}_{2}$, and $0.02 \mathrm{~g} \mathrm{MnSO}_{4}$ in $1000 \mathrm{ml}$ distilled water, $\mathrm{pH}$ 7.2), and incubated at $30{ }^{\circ} \mathrm{C}$ with shaking at $170 \mathrm{rpm}$ for 6 days. Sterilized non-inoculated medium was used as control. All media were autoclaved at $121{ }^{\circ} \mathrm{C}$ for $20 \mathrm{~min}$. Samples were withdrawn periodically at every $24 \mathrm{~h}$ and assessed for bacterial growth, reducing sugar concentration, enzymatic activity, and residual rice straw. All assays were performed with three replicates.

\section{Bacterial growth evaluation}

The bacterial growth was assayed as previously described [17].

\section{Treatment of rice straw by Fenton reagent}

One percentage rice straw $(w / v)$ was added to Erlenmeyer flask $(250 \mathrm{ml})$ with solutions containing $1.25 \mathrm{mM}$ $\mathrm{Fe}^{2+}$ and $176 \mathrm{mM}$ hydrogen peroxide, the $\mathrm{pH}$ of the reaction mixture was adjusted to 3.0 using oxalic acid and

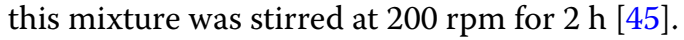

\section{The addition of hydroxyl radical scavenger in culture}

Forty millimolar dimethyl sulfoxide (DMSO), mannitol, thiourea, and ethanol were added to the rice straw medium, respectively.

\section{Determination of residual rice straw}

The residual rice straw biomass was harvested by vacuum filtration and washed twice with distilled water, then dried at $60{ }^{\circ} \mathrm{C}$ for $48 \mathrm{~h}$. Cellulose, hemicellulose, and lignin contents of dried rice straw were determined by Van Soest method [46]. Cellulose content was calculated as the difference between acid detergent fiber (ADF) and acid detergent lignin (ADL). Hemicellulose content was calculated as the difference between neutral detergent fiber (NDF) and ADF, while lignin content was calculated as the difference between ADL and ash content.
Rice straw biomass, cellulose, hemicellulose, and lignindegrading efficiencies were calculated by the following formula:

$$
\begin{aligned}
& \text { Rice straw (cellulose, hemicellulose, lignin) loss (\%) } \\
& \quad=\frac{m_{0}-m_{n}}{m_{0}} \times 100 \%
\end{aligned}
$$

where $m_{0}$ is the initial rice straw weight or (cellulose, hemicellulose, lignin) content, g; $m_{n}$ is the nth day sampling rice straw weight or (cellulose, hemicellulose, lignin) in $g$.

\section{Reducing sugar and lignocellulolytic enzyme assay}

The culture supernatant was collected by centrifugation at 12,000 rpm for $10 \mathrm{~min}$ and used for measurement of reducing sugar concentration, endoglucanase, exoglucanase, xylanase, lignin peroxidase, laccase, and $\mathrm{Fe}^{3+}$. reducing activity. Reducing sugar content was estimated by using DNS method with glucose as the standard [47]. Endoglucanase, exoglucanase, xylanase activities were determined by using carboxymethyl cellulose sodium salt (CMC-Na), filter paper (Whatman grade 1), and birchwood xylan as substrates, respectively $[48,49]$. Concerning that a few of enzymes may be inevitably adsorbed on rice straw, the assayed enzymes in the cultures are proteins in systems except the adsorbed one by substrates. One unit of enzyme activity was defined as the amount of enzyme that catalyzes the release of $1 \mu \mathrm{M}$ reducing sugar (glucose for endoglucanase and exoglucanase, xylose for xylanase) per minute under the specified assay conditions. Lignin peroxidase activity was assayed by monitoring oxidation of veratryl alcohol to veratraldehyde at $310 \mathrm{~nm}\left(\varepsilon 310=9300 \mathrm{M}^{-1} \mathrm{~cm}^{-1}\right)$ according to the procedure of Chen et al. [22]. Laccase activity was performed according to the method of Nakagawa et al. [50] using 2,2,-azino-bis(3-ethylbenzothiazoline-6-sulfonic acid) (ABTS) as substrate and monitoring the production of ABTS radical at $420 \mathrm{~nm}\left(\varepsilon 420=36,000 \mathrm{M}^{-1} \mathrm{~cm}^{-1}\right)$. One unit of lignin peroxidase or laccase activity was defined as the amount of enzyme required to produce $1 \mu \mathrm{M}$ product per minute under the specified assay conditions.

\section{High-performance liquid chromatographic (HPLC) analysis of hydrolysate}

A HPLC system (Agilent 1100) equipped with UVdetector for sugars (monitored at $245 \mathrm{~nm}$ ), furfural, and 5-hydroxymethylfurfural (monitored at $230 \mathrm{~nm}$ ) analysis. A ZORBAX Eclipse XDB-C18 column $(150 \mathrm{~mm} \times 4.6 \mathrm{~mm} \times 5 \mu \mathrm{m})$ (Agilent, USA) was used for the analysis. Sugars were reacted with 1-phenyl3-methyl-5-pyrazolone (PMP) for derivatization before detection. The derivatization procedure was performed as described by Dai et al. [51]. Sugars analysis was carried 
out with acetonitrile-water $(80 / 20, v / v)$ as the mobile phase. The furfural and 5-hydroxymethylfurfural analysis were performed with acetonitrile-water $(85 / 15, v / v)$ as the mobile phase. The flow rate of the eluent was $1 \mathrm{ml} /$ min with a column temperature of $35^{\circ} \mathrm{C}$.

\section{Methane sulfinic acid assay}

The produced methane sulfinic acid during the reaction of hydroxyl radical and DMSO was determined by addition of $1.0 \mathrm{ml}$ sample and $2.0 \mathrm{ml} 15 \mathrm{mM}$ Fast Blue BB salt and reacted at room temperature in the dark, followed by extraction with $3.0 \mathrm{ml}$ of toluene/butanol $(3 / 1, v / v)$. The toluene/butanol phase was washed with $5 \mathrm{ml}$ butanolsaturated water to remove the remaining unreacted diazonium salt and centrifuged. One milliliter of pyridine was added to upper phase to stabilize. The absorbance was determined at $420 \mathrm{~nm}$ against blanks containing all reagents except DMSO. Standards were prepared with 0-50 $\mu \mathrm{M}$ authentic methane sulfinic acid [52].

\section{FTIR spectroscopy analysis}

Samples for FTIR analysis were vacuum-dried and milled into a powder, then mixed with dry $\mathrm{KBr}$ at a ratio of $1 / 200$ $(w / w)$ and homogenized into a very fine powder. FTIR spectroscopy analysis was performed using a Varian 2000 FTIR spectrometer, taking 32 scans for each sample at $4 \mathrm{~cm}^{-1}$ resolution, ranging from 400 to $4000 \mathrm{~cm}^{-1}$.

\section{Py-GC/MS analysis}

Py-GC/MS analysis was performed using a EGA/PY3030D pyrolyzer (Frontier Laboratories, Japan) coupled to a QP2010 ultra gas chromatograph-mass spectrometer (Shimadzu, Japan) with a DB-5 capillary column $(30 \mathrm{~m} \times 0.25 \mathrm{~mm} \times 0.25 \mu \mathrm{m})$ (Agilent, Palo Alto, USA). The pyrolysis was initially set at $200{ }^{\circ} \mathrm{C}$ and held for $1 \mathrm{~min}$, then increased to $600{ }^{\circ} \mathrm{C}$ at $20^{\circ} \mathrm{C} / \mathrm{min}$ and held for $12 \mathrm{~s}$. The GC temperature was started at $80^{\circ} \mathrm{C}$ and held for $1 \mathrm{~min}$, later on increased to $280{ }^{\circ} \mathrm{C}$ at $5{ }^{\circ} \mathrm{C} / \mathrm{min}$ and held for $10 \mathrm{~min}$. The mass spectra of each compound were identified according to the National Institute of Standards and Technology (NIST) library. Quantification of pyrolysis products was based on the peak area of characteristic fragment ions. The relative abundances of each pyrolysis products were calculated as the percentage of the sum of all peak areas.

\section{GC-MS analysis degradation products}

Cultures of $P$. ananatis $\mathrm{Sd}-1$ grew in rice straw were collected on day 3 , then centrifuged at $8000 \mathrm{rpm}$ for $15 \mathrm{~min}$ to remove biomass. Thereafter, supernatants were treated according to Raj et al. [53]. Briefly, supernatants were acidified to $\mathrm{pH} 1-2$ with $12 \mathrm{M} \mathrm{HCl}$ and then extracted with equal volumes of ethyl acetate three times. Extracted liquor was collected and dewatered over anhydrous $\mathrm{Na}_{2} \mathrm{SO}_{4}$. The extract liquor was filtered through filter paper and concentrated to approximately $1 \mathrm{ml}$ by rotary vacuum evaporator. Then $100 \mu \mathrm{l}$ dioxane and $10 \mu \mathrm{l}$ pyridine were added to the sample followed by silylation with $50 \mu \mathrm{l}$ of trimethyl silyl [( $\mathrm{N}, \mathrm{O}$-bis(trimethylsilyl) trifluoroacetamide) BSTFA/trimethylchlorosilane (TMS) $=99 / 1$ $(v / v)]$. The mixture was heated at $60^{\circ} \mathrm{C}$ for 15 min with periodic shaking to dissolve residue. GC-MS analysis of the silylated compounds was performed according to the procedure of Chen et al. [22]. The identification of TMS derivatives derived from bacterial degradation was conducted by comparing their mass spectra with that of the NIST library available on the instrument and by comparing the retention time to the original standards.

\section{Determination of $\mathrm{Fe}^{3+}$-reducing activity}

The $\mathrm{Fe}^{3+}$-reducing activity was performed by monitoring $\mathrm{Fe}^{3+}$-reduction based on formation of the ferrozine$\mathrm{Fe}^{2+}$ complex [10]. The reaction mixture $(3 \mathrm{ml})$ contained $50 \mu \mathrm{M} \mathrm{FeCl}_{3}, 10 \mathrm{mM}$ ferrozine in $1 \mathrm{M}$ acetic acid, $1 \mathrm{M}$ sodium acetate buffer ( $\mathrm{pH} 4.5)$, and $2 \mathrm{ml}$ sample. The change in absorbance of reaction at $562 \mathrm{~nm}$ was immediately recorded using a UV-visible spectrophotometer within $3 \mathrm{~min}$. One unit of $\mathrm{Fe}^{3+}$-reducing activity was defined as the rate of absorbance increase at $562 \mathrm{~nm}$ per minute.

\section{Total iron ion concentration assay}

Total iron ion concentration was determined by a colorimetric ferrozine assay [54]. One hundred milliliters of the sample were mixed with $100 \mu \mathrm{l} 10 \mathrm{mM} \mathrm{HCl}$. Then $100 \mu \mathrm{l}$ of the iron-detection reagent $(6.5 \mathrm{mM}$ ferrozine, $6.5 \mathrm{mM}$ neocuproine, $2.5 \mathrm{M}$ ammonium acetate, and $1 \mathrm{M}$ ascorbic acid dissolved in water) was added to the mixture. After 30 min incubation, absorbance was immediately recorded at $562 \mathrm{~nm}$ using a UV-visible spectrophotometer. Standard $\mathrm{FeCl}_{3}(0-50 \mu \mathrm{M})$ was used to quantify sample measurements.

\section{Total secreted proteins extraction}

Cultures of $P$. ananatis Sd-1 grew in rice straw were collected on day 3. After filtering, biomass and supernatant were separated by centrifugation $(4000 \mathrm{rpm}, 10 \mathrm{~min}$, $4{ }^{\circ} \mathrm{C}$ ) and the supernatant was further clarified by filtration through $0.2 \mu \mathrm{m}$ membranes (Millipore corporation, Billerica, MA). The supernatant protein fraction was concentrated using acetone precipitation [55]. The precipitated protein pellets were dissolved in an appropriate volume of phosphate buffer solution $(0.02 \mathrm{M}, \mathrm{pH}$ 7.2), then used for the $\mathrm{Fe}^{3+}$-reducing activity assays. Protein concentrations were determined using BCA protein assay kit (Dingguo, Beijing, China). 
Total RNA extraction and complementary DNA synthesis The bacterial cells were harvested from rice straw- and glucose-containing cultures at every $24 \mathrm{~h}$ intervals by centrifugation at $4000 \mathrm{rpm}$ for $10 \mathrm{~min}$ at $4{ }^{\circ} \mathrm{C}$. Total RNA was extracted with TRIzol reagent (Invitrogen, Carlsbad, USA) according to the manufacturer's specifications. Amplification of complementary DNA (cDNA) was carried out using PrimeScript RT reagent Kit (Takara, Dalian, China) according to the manufacturer's instructions.

\section{Quantitative real-time PCR}

Primers used for quantitative real-time PCR (RT-qPCR) were designed using Beacon Designer 7.7 software (Additional file 7: Table S2). The RT-qPCR reactions were carried out using Mx3000P thermal cycler (Stratagene, Santa Clara, CA) and normalized using $16 \mathrm{~S}$ ribosomal RNA expression levels as the internal reference. Reactions were conducted using SYBR ${ }^{\circledR}$ Premix Ex Taq ${ }^{\text {TM }}$ II (Tli RnaseH Plus) (Takara, Dalian, China) with $20 \mu \mathrm{l}$ reaction mixture containing $10 \mu \mathrm{l}$ of $2 \times$ SYBR Premix Ex Taq II, $0.4 \mu \mathrm{M}$ of primers, $0.05 \mu \mathrm{g}$ of cDNA template, and nuclease-free water. The applied cycling conditions were as follows: initial denaturation at $95{ }^{\circ} \mathrm{C}$ for $30 \mathrm{~s}$, followed by 40 cycles of $95^{\circ} \mathrm{C}$ for $5 \mathrm{~s}$, then $60{ }^{\circ} \mathrm{C}$ for $30 \mathrm{~s}$, and $72{ }^{\circ} \mathrm{C}$ for $30 \mathrm{~s}$. A melting curve analysis was performed after amplification reaction to verify primer specificity. The specificity of the primers was confirmed by the presence of a single peak of the melting curve. All reactions were performed in triplicate. Relative transcript levels were determined by $2^{-\Delta \Delta C t}$ method as described previously: normalizing the gene expression levels in rice strawcontaining culture to that in glucose-containing culture, where expression level of the gene in glucose-containing culture at the first day was set to one [17].

\section{Glucose-methanol-choline (GMC) oxidoreductase activity assay}

The intracellular proteins from $P$. ananatis $\mathrm{Sd}-1$ were extracted from harvested bacterial cells from rice strawand glucose-containing cultures at every $24 \mathrm{~h}$ intervals by sonication, and centrifuged $\left(12,000 \mathrm{rpm}, 4{ }^{\circ} \mathrm{C}, 10 \mathrm{~min}\right)$. GMC oxidoreductase activity was determined like pyranose oxidase by monitoring the production of ABTS radical at $420 \mathrm{~nm}\left(\varepsilon 420=36,000 \mathrm{M}^{-1} \mathrm{~cm}^{-1}\right)$ based on a coupled reaction of horseradish peroxidase and its substrate ABTS as Leitner et al. [56] described. One unit of enzyme activity was defined as the amount of enzyme required for oxidation of $2 \mu \mathrm{M}$ ABTS per minute under the assay conditions described above.

\section{Hydrogen peroxide concentration determination}

Cultures of $P$. ananatis $\mathrm{Sd}-1$ that grew in rice straw and glucose media were harvested at $24 \mathrm{~h}$ intervals, centrifuged (8000 rpm, $\left.4{ }^{\circ} \mathrm{C}, 5 \mathrm{~min}\right)$, and supernatants collected. A hydrogen peroxide assay kit (Beyotime Institute of Biotechnology, Haimen, China) was used for determination of hydrogen peroxide concentration according to the manufacturer's recommended protocol.

\section{Additional files}

Additional file 1: Figure S1. Growth of bacterial strain and reducing sugars production during the degradation of rice straw by $P$. ananatis $\mathrm{Sd}-1$ in the presence of DMSO.

Additional file 2: Figure S2. The percentage of weight loss for total rice straw, cellulose, hemicellulose and lignin in the presence of mannitol (RS + mannitol), thiourea (RS + thiourea), ethanol (RS + ethanol) and absence (RS) of hydroxyl radical scavenger after 6 days incubation (a); enzymes activities of endoglucanase, exoglucanase, xylanase, lignin peroxidase and laccase during the degradation of rice straw by $P$. ananatis Sd-1 in the presence of mannitol (b), thiourea (c) and ethanol (d).

Additional file 3: Table S1. Sugars, furfural and 5-hydroxymethylfurfural (HMF) derived from rice straw during the P. ananatis Sd-1 and Fenton reagent treatment.

Additional file 4: Figure S3. Determination of methane sulfinic acid in the presence of DMSO during the degradation process of rice straw by $P$. ananatis Sd-1.

Additional file 5: Figure S4. FTIR spectra of rice straw before (control) and after 6 days treatment by P. ananatis Sd-1 or Fenton reagent. The black arrow indicated the appearance of new peak located in the carbonyl groups region.

Additional file 6: Figure S5. Total ion chromatograph (TIC) of ethyl acetate extract analysed as TMS derivatives from control (a) and $P$. ananatis Sd-1 degraded rice straw after 3 days incubation (b).

Additional file 7: Table S2. Primers used for quantitative real time-PCR

\section{Abbreviations}

Py-GC/MS: pyrolysis gas chromatography-mass spectrometry; FTIR: Fourier transform infrared spectroscopy; GMC: glucose-methanol-choline; DMSO: dimethylsulfoxide; GC-MS: gas chromatography-mass spectrometry; TIC: total ion chromatogram; RT: retention time; RT-qPCR: quantitative real-time polymerase chain reaction; ADF: acid detergent fiber; ADL: acid detergent lignin; NDF: neutral detergent fiber; HPLC: high-performance liquid chromatographic; PMP: 1-phenyl-3-methyl-5-pyrazolone.

\section{Authors' contributions}

JSM designed the experiment, carried out the rice straw degradation analysis, determination of residual rice straw, enzymatic activity assay, methane sulfinic acid and iron ion concentration assay experiments, collected and analyzed the results, and drafted the manuscript. KKZ carried out the reducing sugar assay and qRT-PCR experiments and helped to revise the manuscript. MH participated in the design of the study, carried out bacterial strain growth measurement, high-performance liquid chromatographic analysis of hydrolysate, and helped to draft the manuscript. SBH participated in the design of the study and helped to draft the manuscript. YHZ provided the original idea, performed the statistical analysis, and drafted the manuscript. XML conceived the study, contributed to enzymatic activity results analysis, and helped to draft the manuscript. BL participated in the FTIR spectroscopy analysis and helped to revise the manuscript. CYT participated in the Py-GC/MS experiment and helped to revise the manuscript. QL performed the GC-MS experiments and helped to revise the manuscript. JRZ performed the $\mathrm{Fe}^{3+}$-reducing activity analysis and helped to revise the manuscript. YG participated in the design of the study and coordination and helped to revise the manuscript. TX participated in the secreted proteins extraction experiment and helped to revise the manuscript. YL performed the hydrogen peroxide concentration assay and helped to revise the manuscript. All authors read and approved the final manuscript. 


\begin{abstract}
Author details
${ }^{1}$ Hunan Province Key Laboratory of Plant Functional Genomics and Developmental Regulation, College of Biology, Hunan University, Changsha 410008, Hunan, People's Republic of China. ${ }^{2}$ Department of Genetics, Institute for Plant Biotechnology, Stellenbosch University, Private Bag X1, Matieland 7602, South Africa. ${ }^{3}$ DNA Sequencing Unit, Central Analytical Facility, Stellenbosch University, Private Bag X1, Matieland 7602, South Africa.
\end{abstract}

\section{Acknowledgements}

The authors would like to acknowledge the financial support from the National Natural Science Foundation of China (51378191).

\section{Competing interests}

The authors declare that they have no competing interests.

\section{Availability of supporting data}

All supporting data are provided with this submission and additional files are detailed below.

\section{Consent for publication}

The authors give their consent for the publication of the manuscript and all supporting documents and data.

\section{Funding}

This work was financially supported by the National Natural Science Foundation of China (51378191).

Received: 1 August 2016 Accepted: 24 September 2016

Published online: 06 October 2016

\section{References}

1. Vispute TP, Zhang H, Sanna A, Xiao R, Huber GW. Renewable chemical commodity feedstocks from integrated catalytic processing of pyrolysis oils. Science. 2010;330:1222-7.

2. Sanchez C. Lignocellulosic residues: biodegradation and bioconversion by fungi. Biotechnol Adv. 2009;27:185-94.

3. Mathews SL, Pawlak J, Grunden AM. Bacterial biodegradation and bioconversion of industrial lignocellulosic streams. Appl Microbiol Biotechnol. 2015;99:2939-54.

4. Goodell B, Jellison J, Liu J, Daniel G, Paszczynski A, Fekete F, et al. Low molecular weight chelators and phenolic compounds isolated from wood decay fungi and their role in the fungal biodegradation of wood. J Biotechnol. 1997;53:133-62.

5. Guerra A, Mendonça R, Ferraz A. Molecular weight distribution of wood components extracted from Pinus taeda biotreated by Ceriporiopsis subvermispora. Enzym Microb Technol. 2003;33:12-8.

6. Singh D, Zeng J, Laskar DD, Deobald L, Hiscox WC, Chen S. Investigation of wheat straw biodegradation by Phanerochaete chrysosporium. Biomass Bioenergy. 2011;35:1030-40.

7. Salvachúa D, Martínez AT, Tien M, López-Lucendo MF, García F, de los Ríos $V$, et al. Differential proteomic analysis of the secretome of Irpex lacteus and other white-rot fungi during wheat straw pretreatment. Biotechnol Biofuels. 2013;6:1

8. Saritha M, Arora A, Nain L. Pretreatment of paddy straw with Trametes hirsuta for improved enzymatic saccharification. Bioresour Technol. 2012;104:459-65.

9. Arantes $V$, Jellison J, Goodell B. Peculiarities of brown-rot fungi and biochemical Fenton reaction with regard to their potential as a model for bioprocessing biomass. Appl Microbiol Biotechnol. 2012;94:323-38.

10. Eastwood DC, Floudas D, Binder M, Majcherczyk A, Schneider P, Aerts A, et al. The plant cell wall-decomposing machinery underlies the functional diversity of forest fungi. Science. 2011;333:762-5.

11. Zhu N, Liu J, Yang J, Lin Y, Yang Y, Ji L, et al. Comparative analysis of the secretomes of Schizophyllum commune and other wood-decay basidiomycetes during solid-state fermentation reveals its unique lignocellulose-degrading enzyme system. Biotechnol Biofuels. 2016;9:42.
12. Arantes V, Milagres AM, Filley TR, Goodell B. Lignocellulosic polysaccharides and lignin degradation by wood decay fungi: the relevance of nonenzymatic Fenton-based reactions. J Ind Microbiol Biotechnol. 2011;38:541-55.

13. Grinhut T, Salame TM, Chen Y, Hadar Y. Involvement of ligninolytic enzymes and Fenton-like reaction in humic acid degradation by Trametes sp. Appl Microbiol Biotechnol. 2011;91:1131-40.

14. Xie S, Qin X, Cheng Y, Laskar D, Qiao W, Sun S, et al. Simultaneous conversion of all cell wall components by an oleaginous fungus without chemiphysical pretreatment. Green Chem. 2015;17:1657-67.

15. Levasseur A, Drula E, Lombard V, Coutinho PM, Henrissat B. Expansion of the enzymatic repertoire of the CAZy database to integrate auxiliary redox enzymes. Biotechnol Biofuels. 2013;6:1.

16. Xiong XQ, Liao HD, Ma JS, Liu XM, Zhang LY, Shi XW, et al. Isolation of a rice endophytic bacterium, Pantoea sp. Sd-1, with ligninolytic activity and characterization of its rice straw degradation ability. Lett Appl Microbiol. 2014;58:123-9.

17. Ma J, Zhang K, Liao H, Hector SB, Shi X, Li J, et al. Genomic and secretomic insight into lignocellulolytic system of an endophytic bacterium Pantoea ananatis Sd-1. Biotechnol Biofuels. 2016;9:25

18. Kumar M, Revathi K, Khanna S. Biodegradation of cellulosic and lignocellulosic waste by Pseudoxanthomonas sp. R-28. Carbohydr Polym. 2015;134:761-6.

19. Hui W, Jiajia L, Yucai L, Peng G, Xiaofen W, Kazuhiro M, et al. Bioconversion of un-pretreated lignocellulosic materials by a microbial consortium XDC-2. Bioresour Technol. 2013;136:481-7.

20. Wei D, Houtman CJ, Kapich AN, Hunt CG, Cullen D, Hammel KE. Laccase and its role in production of extracellular reactive oxygen species during wood decay by the brown rot basidiomycete Postia placenta. Appl Microbiol Biotechnol. 2010;76:2091-7.

21. Chen Y, Chai L, Tang C, Yang Z, Zheng Y, Shi Y, et al. Kraft lignin biodegradation by Novosphingobium sp. B-7 and analysis of the degradation process. Bioresour Technol. 2012;123:682-5.

22. Chen YH, Chai LY, Zhu YH, Yang ZH, Zheng Y, Zhang H. Biodegradation of kraft lignin by a bacterial strain Comamonas sp. B-9 isolated from eroded bamboo slips. J Appl Microbiol. 2012;112:900-6.

23. Shi Y, Chai L, Tang C, Yang Z, Zhang H, Chen R, et al. Characterization and genomic analysis of kraft lignin biodegradation by the beta-proteobacterium Cupriavidus basilensis B-8. Biotechnol Biofuels. 2013;6:1.

24. Jung YH, Kim HK, Park HM, Park YC, Park K, Seo JH, et al. Mimicking the Fenton reaction-induced wood decay by fungi for pretreatment of lignocellulose. Bioresour Technol. 2015;179:467-72.

25. Jiang Y, Loh TP. Catalytic and direct methyl sulfonylation of alkenes and alkynes using a methyl sulfonyl radical generated from a DMSO, dioxygen and copper system. Chem Sci. 2014;5:4939-43.

26. Forney $L$, Reddy CA, Tien M, Aust SD. The involvement of hydroxyl radical derived from hydrogen peroxide in lignin degradation by the white rot fungus Phanerochaete chrysosporium. J Biol Chem. 1982;257:11455-62.

27. Jeong SY, Lee JW. Sequential Fenton oxidation and hydrothermal treatment to improve the effect of pretreatment and enzymatic hydrolysis on mixed hardwood. Bioresour Technol. 2016;200:121-7.

28. Canam T, Town JR, Tsang A, McAllister TA, Dumonceaux TJ. Biological pretreatment with a cellobiose dehydrogenase-deficient strain of Trametes versicolor enhances the biofuel potential of canola straw. Bioresour Technol. 2011:102:10020-7.

29. Hammel KE, Kapich AN, Jensen KA, Ryan ZC. Reactive oxygen species as agents of wood decay by fungi. Enzym Microb Technol. 2002;30:445-53.

30. Henriksson G, Johansson G, Pettersson G. A critical review of cellobiose dehydrogenases. J Biotechnol. 2000;78:93-113.

31. Shah V, Baldrian P, Eichlerova I, Dave R, Madamwar D, Nerud F, et al. Influence of dimethyl sulfoxide on extracellular enzyme production by Pleurotus ostreatus. Biotechnol Lett. 2006;28:651-5.

32. Filley TR, Cody GD, Goodell B, Jellison J, Noser C, Ostrofsky A. Lignin demethylation and polysaccharide decomposition in spruce sapwood degraded by brown rot fungi. Org Geochem. 2002;33:111-4.

33. Rineau F, Roth D, Shah F, Smits M, Johansson T, Canback B, et al. The ectomycorrhizal fungus Paxillus involutus converts organic matter in plant litter using a trimmed brown-rot mechanism involving Fenton chemistry. Environ Microbiol. 2012;14:1477-87. 
34. Chen F, Xie Y, He J, Zhao J. Photo-Fenton degradation of dye in methanolic solution under both UV and visible irradiation. J Photochem Photobiol A Chem. 2001;138:139-46.

35. Martinez D, Challacombe J, Morgenstern I, Hibbett D, Schmoll M, Kubicek CP, et al. Genome, transcriptome, and secretome analysis of wood decay fungus Postia placenta supports unique mechanisms of lignocellulose conversion. Proc Natl Acad Sci USA. 2009;106:1954-9.

36. Gligorovski S, Strekowski R, Barbati S, Vione D. Environmental implications of hydroxyl radicals $(\mathrm{OH} \cdot)$. Chem Rev. 2015;115:13051-92.

37. Baldrian P, Valaskova V. Degradation of cellulose by basidiomycetous fungi. FEMS Microbiol Rev. 2008;32:501-21.

38. Tanaka H, Yoshida G, Baba Y, Matsumura K, Wasada H, Murata J, et al. Characterization of a hydroxyl-radical-producing glycoprotein and its presumptive genes from the white-rot basidiomycete Phanerochaete chrysosporium. J Biotechnol. 2007;128:500-11.

39. Suzuki MR, Hunt CG, Houtman CJ, Dalebroux ZD, Hammel KE. Fungal hydroquinones contribute to brown rot of wood. Environ Microbiol. 2006;8:2214-23.

40. Shah F, Schwenk D, Nicolas C, Persson P, Hoffmeister D, Tunlid A. Involutin is an $\mathrm{Fe}^{3+}$ reductant secreted by the ectomycorrhizal fungus Paxillus involutus during Fenton-based decomposition of organic matter. Appl Environ Microbiol. 2015;81:8427-33.

41. Aguiar A, Ferraz A. Fe ${ }^{3+}$ - and $\mathrm{Cu}^{2+}$-reduction by phenol derivatives associated with Azure $B$ degradation in Fenton-like reactions. Chemosphere. 2007;66:947-54

42. Aguiar A, de Souza-Cruz PB, Ferraz A. Oxalic acid, $\mathrm{Fe}^{3+}$-reduction activity and oxidative enzymes detected in culture extracts recovered from Pinus taeda wood chips biotreated by Ceriporiopsis subvermispora. Enzym Microb Technol. 2006;38:873-8.

43. Ferreira P, Carro J, Serrano A, Martinez AT. A survey of genes encoding $\mathrm{H}_{2} \mathrm{O}_{2}$-producing GMC oxidoreductases in 10 Polyporales genomes. Mycologia. 2015;107:1105-19.

44. Ai M-Q, Wang F-F, Zhang Y-Z, Huang F. Purification of pyranose oxidase from the white rot fungus Irpex lacteus and its cooperation with laccase in lignin degradation. Process Biochem. 2014;49:2191-8.
45. Kato DM, Elia N, Flythe M, Lynn BC. Pretreatment of lignocellulosic biomass using Fenton chemistry. Bioresour Technol. 2014;162:273-8.

46. Van Soest PJ, Robertson JB, Lewis BA. Methods for dietary fiber, neutral detergent fiber, and nonstarch polysaccharides in relation to animal nutrition. J Dairy Sci. 1991;74:3583-97.

47. Miller GL. Use of dinitrosalicylic acid reagent for determination of reducing sugar. Anal Chem. 1959;31:426-8.

48. Ghose TK. Measurement of cellulase activities. Pure Appl Chem. 1987;59:257-68.

49. Bailey MJ, Biely P, Poutanen K. Interlaboratory testing of methods for assay of xylanase activity. J Biotechnol. 1992;23:257-70.

50. Nakagawa Y, Sakamoto Y, Kikuchi S, Sato T, Yano A. A chimeric laccase with hybrid properties of the parental Lentinula edodes laccases. Microbiol Res. 2010;165:392-401.

51. Dai J, Wu Y, S-w Chen, Zhu S, H-p Yin, Wang M, et al. Sugar compositional determination of polysaccharides from Dunaliella salina by modified RP-HPLC method of precolumn derivatization with 1-phenyl-3-methyl5-pyrazolone. Carbohydr Polym. 2010;82:629-35.

52. Babbs CF, Gale MJ. Colorimetric assay for methanesulfinic acid in biological samples. Anal Biochem. 1987;163:67-73.

53. Raj A, Krishna Reddy MM, Chandra R. Identification of low molecular weight aromatic compounds by gas chromatography-mass spectrometry (GC-MS) from kraft lignin degradation by three Bacillus sp. Int Biodeterior Biodegrad. 2007;59:292-6.

54. Riemer J, Hoepken HH, Czerwinska H, Robinson SR, Dringen R. Colorimetric ferrozine-based assay for the quantitation of iron in cultured cells. Anal Biochem. 2004;331:370-5

55. Tiwari R, Singh S, Nain PK, Rana S, Sharma A, Pranaw K, et al. Harnessing the hydrolytic potential of phytopathogenic fungus Phoma exigua ITCC 2049 for saccharification of lignocellulosic biomass. Bioresour Technol. 2013;150:228-34

56. Leitner C, Volc J, Haltrich D. Purification and characterization of pyranose oxidase from the white rot fungus Trametes multicolor. Appl Environ Microbiol. 2001;67:3636-44.

\section{Submit your next manuscript to BioMed Central and we will help you at every step:}

- We accept pre-submission inquiries

- Our selector tool helps you to find the most relevant journal

- We provide round the clock customer support

- Convenient online submission

- Thorough peer review

- Inclusion in PubMed and all major indexing services

- Maximum visibility for your research

Submit your manuscript at www.biomedcentral.com/submit
() Biomed Central 